Western University

Scholarship@Western

Civil and Environmental Engineering

Civil and Environmental Engineering

Publications

Department

2020

\title{
Performance-Based Design of RC Columns using an Equivalent Standard Fire
}

Robert T. Kuehnen

The University of Western Ontaro

Maged A. Youssef

Western University, youssef@uwo.ca

Salah El-Din F. El-Fitiany

The University of Western Ontario

Follow this and additional works at: https://ir.lib.uwo.ca/civilpub

Part of the Structural Engineering Commons

\section{Citation of this paper:}

Kuehnen, Robert T.; Youssef, Maged A.; and El-Fitiany, Salah El-Din F., "Performance-Based Design of RC Columns using an Equivalent Standard Fire" (2020). Civil and Environmental Engineering Publications.

188.

https://ir.lib.uwo.ca/civilpub/188 


\title{
Performance-Based Design of RC Columns using an Equivalent Standard Fire
}

\author{
Kuehnen, R.T. ${ }^{1}$, Youssef, M.A. ${ }^{1,3}$, and El-Fitiany, S. $^{2}$ \\ ${ }^{1}$ Western University, Department of Civil and Environmental Engineering, London, ON N6A 5B9, Canada \\ ${ }^{2}$ Alexandria University, Department of Civil Engineering, Alexandria, Egypt
}

\section{Abstract}

The extreme variability of natural compartment fires poses a significant challenge in the process of performance-based fire design. To eliminate this variability, the severity of a natural fire can be related to that of a standard fire duration, known as a time equivalent $\left(t_{e}\right)$. In this paper, the applicability of a time equivalent, which is based on the average internal temperature profile (AITP) that develops within RC beams exposed to fire from three sides, is examined for RC columns exposed to fire from four sides. A parametric study is presented to examine the suitability of the existing AITP $t_{e}$ in representing the internal temperatures of RC columns. The accuracy of the AITP $t_{e}$ in approximating column performance, is judged based on the moment-curvature, axial loadaxial strain, and moment-axial load relationships during fire exposure. Comparison with existing methods is provided to further demonstrate the superior suitability of the AITP $t_{e}$ in representing natural fire severity for RC columns.

Keywords: Standard Fire, Natural Fire, Reinforced Concrete, RC Columns, Performance-Based Design, Time Equivalent, Moment-Axial Relationship

${ }^{3}$ Corresponding Author. Tel.: +1 519661 2111, 88661; E-mail address: youssef@uwo.ca (Youssef, M.A.).

(C) 2020. This manuscript version is made available under the CC-BY-NC-ND 4.0 license http://creativecommons.org/licenses/by-nc-nd/4.0/ 


\section{Introduction}

Structural collapse during fire events poses a serious safety risk for occupants and first responders. Beyond the prescriptive fire safety measures commonly provided in the North American standards (NFPA 1, 2018), performance-based fire design can be undertaken to ensure structural integrity during a building fire. The complexity of fire events has previously posed a barrier to conduct such a design; but with the ongoing development of simplified analysis methods, performancebased fire design has become a feasible reality. Procedures for implementing performance-based fire design are included in the most recent release of ASCE 7 (2016). One simplification that can be used in a practical analysis, is the estimation of a natural fire severity using a standard fire with a time equivalent duration $\left(t_{e}\right)$. Using a time equivalent, the wealth of existing data, testing, and material models utilizing standard fire curves can be directly related to natural events for conducting simplified performance-based fire design (Buchanan, 2001).

Kuehnen and Youssef (2019) proposed a time equivalent that was based on the average internal temperature profile (AITP) that develops within a RC beam exposed to fire from three sides. A typical column undergoes heating on all four faces. Although a seemingly minor difference, the interaction of 4-sided heating has a significant effect on the internal temperature gradients, and in turn the section behaviour. Existing time equivalent methods have failed to make the distinction between the different heating scenarios, and to the best of the author's knowledge, no general method is available to evaluate the time equivalent for RC columns undergoing 4-sided natural fire exposure. In this paper, the suitability of the proposed AITP $t_{e}$ is assessed for the application of 4-sided heating by examining section internal temperatures and mechanical responses.

(C) 2020. This manuscript version is made available under the CC-BY-NC-ND 4.0 license http://creativecommons.org/licenses/by-nc-nd/4.0/ 


\section{Average Internal Temperature Profile for RC Columns}

The application of AITPs was first proposed by El-Fitiany and Youssef (2009) as a simplified technique to evaluate the two-dimensional thermal gradients that develop within RC crosssections during fire exposure. An AITP describes a section's internal temperatures as a function of depth, allowing for the analysis of RC elements resisting axial loads and uniaxial bending. Suitability of AITPs in representing section temperature gradients for performance-based design has been proven by El-Fitiany and Youssef (2017), Alhadid (2017), Youssef et al. (2015), El-Fitiany and Youssef (2014), and El-Fitiany and Youssef (2009). To develop an AITP, a concrete section is first divided into a fine two-way mesh. Heat transfer is conducted using any acceptable method, such as the finite difference method provided by Lie (1992). Throughout the heat transfer process, the maximum temperature experienced in each mesh block is recorded. At the end of the fire exposure, the meshed units are grouped into horizontal layers of equal height, and the average temperature for each layer is calculated. Subsequently, the AITP represents the maximum averaged temperature experienced by each layer throughout the fire event. Figure 1 displays an example of the AITP developed for a $400 \times 400 \mathrm{~mm}$ column and a $400 \times 400 \mathrm{~mm}$ beam during exposure to a 1-hr ISO standard fire (ISO 834, 2014). The AITP consists of highly-variable (nonlinear) zones near the fire-exposed surfaces, and a constant zone (linear) near the core where temperatures are relatively consistent. For columns, the presence of heating along the top surface of the element creates a profile with two variable zones. As a result, the AITP for columns deviates markedly from that of beams.

(c) 2020. This manuscript version is made available under the CC-BY-NC-ND 4.0 license http://creativecommons.org/licenses/by-nc-nd/4.0/ 


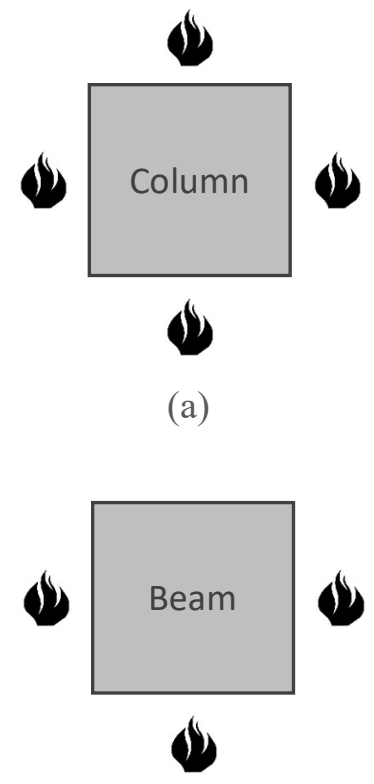

(b)

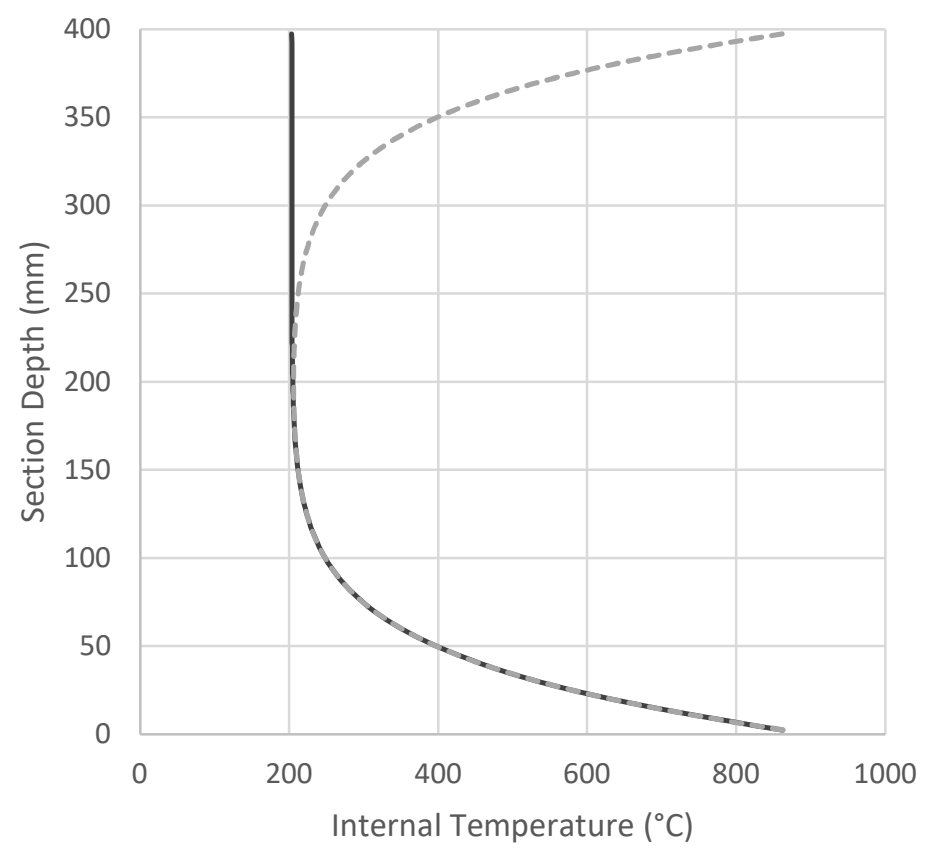

(c)

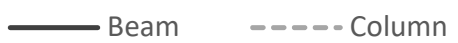

Fig. 1: Column and Beam Exposed to 1-hr ISO Standard Fire (a) 4-Sided Heating, (b) 3-Sided Heating, and (c) AITP

\section{AITP Time Equivalent Methodology}

The AITP $t_{e}$ is based on the correlation of the AITP developed by a selected design-natural fire (AITP-D) and a standard fire with a specific duration (AITP-S). The AITP $t_{e}$ is estimated by iterating the duration of the standard fire until the AITP-S has equal or larger temperatures at every layer when compared to AITP-D (Kuehnen and Youssef, 2019). Using this methodology, the AITP $t_{e}$ can be used to provide a conservative estimate of the internal temperatures within a section. Equation 1 a was developed as a general relationship to calculate the AITP $t_{e}$ for RC beams undergoing 3sided fire exposure based on ISO standard fire (ISO 834, 2014). The maximum fire temperature, $T_{\max }\left({ }^{\circ} \mathrm{C}\right)$; the corresponding time, $t_{\max }(\min ) ;$ and the overall duration of the fire, $t_{\text {final }}(\min )$; were 
selected to define the general equation. Equation 1 was derived for concrete beams with width $\left(b_{c}\right)$ of $250 \mathrm{~mm}$ and height $\left(h_{c}\right)$ of $500 \mathrm{~mm}$. To account for other section dimensions, the calculated $t_{e}$ shall be multiplied by a size adjustment factor $\left(\psi_{\text {size }}\right)$ given by Equation $1 \mathrm{~b}$. The valid range for application of $t_{e}$ and $\psi_{\text {size }}$ is detailed in Table 1 along with the coefficients for the equations.

$$
\begin{aligned}
& t_{e}=A+B t_{\text {max }}+C t_{\text {final }}+D T_{\text {max }}+E t_{\text {max }}^{2}+F t_{\text {final }}^{2}+G T_{\text {max }}^{2} \\
& +H t_{\text {max }} t_{\text {final }}+I t_{\text {max }} T_{\text {max }}+J t_{\text {final }} T_{\text {max }} \\
& \psi_{\text {size }}=\left\{\begin{array}{l}
1.0\left\{\begin{array}{l}
\text { for } b c<300 \mathrm{~m} \\
\text { for conservative } t_{e} \text { when } T_{\text {max }}>1150^{\circ} \mathrm{C} \\
\text { for conservative } t_{e} \text { when } t_{e}>180 \mathrm{~min}
\end{array}\right. \\
A+B t_{\text {max }}+C t_{\text {final }}+D T_{\text {max }} \\
+b_{c}\left(E+F t_{\text {max }}+G t_{\text {final }}+H T_{\text {max }}\right) \geq 1.0
\end{array}\right.
\end{aligned}
$$

\begin{tabular}{|c|c|c|c|c|c|c|}
\hline \multirow{6}{*}{ 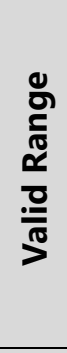 } & \multirow{6}{*}{$\begin{array}{l}\mathrm{b}_{\mathrm{c}}(\mathrm{mm}) \\
\mathrm{h}_{\mathrm{c}}(\mathrm{mm}) \\
\mathrm{t}_{\max }(\min ) \\
\mathrm{t}_{\text {final }}(\mathrm{min}) \\
\mathrm{T}_{\max }\left({ }^{\circ} \mathrm{C}\right)\end{array}$} & \multicolumn{4}{|c|}{$t_{e}$ (Eq. 1a) } & $\psi_{\text {size }}$ (Eq. 1b) \\
\hline & & \multicolumn{4}{|c|}{250} & $200-800$ \\
\hline & & \multicolumn{4}{|c|}{500} & $300-800$ \\
\hline & & \multicolumn{4}{|c|}{$15-115$} & $15-115$ \\
\hline & & \multicolumn{4}{|c|}{$20-240$} & $20-240$ \\
\hline & & $350-750$ & $750-950$ & $950-1100$ & $1100-1200$ & $350-1200$ \\
\hline \multirow{10}{*}{ 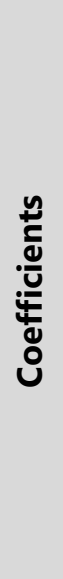 } & $A$ & 8.685 & 2.370 & 566.30 & 4404.0 & 0.819 \\
\hline & B & -0.0829 & -0.0893 & -0.465 & -5.745 & $3.78 \times 10^{-4}$ \\
\hline & C & 0.0324 & 0.0446 & 1.188 & 1.039 & $-2.23 \times 10^{-4}$ \\
\hline & D & -0.0428 & -0.0186 & -1.332 & -8.177 & $1.82 \times 10^{-4}$ \\
\hline & $E$ & $-4.74 \times 10^{-4}$ & $-9.42 \times 10^{-4}$ & $-20.00 \times 10^{-4}$ & $-80.87 \times 10^{-4}$ & 1.037 \\
\hline & $\mathrm{F}$ & $-4.16 \times 10^{-4}$ & $-7.39 \times 10^{-4}$ & 0.0 & $2.99 \times 10^{-4}$ & $-27.00 \times 10^{-4}$ \\
\hline & G & $0.66 \times 10^{-4}$ & $0.35 \times 10^{-4}$ & $7.95 \times 10^{-4}$ & $38.36 \times 10^{-4}$ & $27.15 \times 10^{-4}$ \\
\hline & $\mathrm{H}$ & $1.57 \times 10^{-4}$ & $4.77 \times 10^{-4}$ & $-3.07 \times 10^{-4}$ & $-17.80 \times 10^{-4}$ & $-10.75 \times 10^{-4}$ \\
\hline & I & $5.33 \times 10^{-4}$ & $5.40 \times 10^{-4}$ & $12.05 \times 10^{-4}$ & $69.36 \times 10^{-4}$ & --- \\
\hline & J & $3.70 \times 10^{-4}$ & $4.71 \times 10^{-4}$ & $-9.00 \times 10^{-4}$ & $-8.40 \times 10^{-4}$ & --- \\
\hline
\end{tabular}

Table 1: Valid Range and Coefficients for Equation 1

(c) 2020. This manuscript version is made available under the CC-BY-NC-ND 4.0 license http://creativecommons.org/licenses/by-nc-nd/4.0/ 


\section{Application of the AITP $t_{e}$ for RC Columns}

In this section, the previously developed AITP $t_{e}$ equation for 3-sided fire exposure, is evaluated in view of 4-sided exposure. A parametric study was conducted to determine the suitability of the AITP $t_{e}$ for a wide range of possible design fire exposures and column cross-section dimensions.

\subsection{Test Parameters}

Natural design fires were constructed using the defining parameters: $t_{\text {max }}, t_{\text {final }}$ and $T_{\max }$. Using these parameters, values were selected to develop design fires at reasonable time and temperature intervals. Values for $t_{\max }$ were chosen at 5-min intervals until $30 \mathrm{~min}$, then at 17-min intervals until 115 min; values for $t_{\text {final }}$ were chosen at 20 -min intervals throughout; and $T_{\max }$ values were chosen starting from $350^{\circ} \mathrm{C}$ at $100^{\circ} \mathrm{C}$ intervals until $650^{\circ} \mathrm{C}$, then at $50^{\circ} \mathrm{C}$ intervals until $1200^{\circ} \mathrm{C}$. To extrapolate the defining parameters into a full design fire curve, the Eurocode equations were adopted for the heating branch and a linear profile was used for the cooling branch (EN 1991-12, 2002). In total 1290 design fires were used in the evaluation.

RC cross-sections were evaluated with width and height combinations of $250 \times 250,250 \times 500$, $400 \times 400,400 \times 500,600 \times 500,600 \times 600,800 \times 500$ and $800 \times 800 \mathrm{~mm}$. Normal strength concrete (NSC) with siliceous aggregate was consistently used throughout the study. The thermal properties of NSC with siliceous aggregate were taken from Lie (1992). Considering the 1290 design fires and eight cross-sections, 10,320 test cases were analyzed based on the AITP $t_{e}$.

(C) 2020. This manuscript version is made available under the CC-BY-NC-ND 4.0 license http://creativecommons.org/licenses/by-nc-nd/4.0/ 


\subsection{Study Results}

AITP $t_{e}$ values were initially derived for the $250 \times 500,400 \times 500,600 \times 500$, and $800 \times 500$ sections considering 3-sided and 4-sided exposure using the methodology explained in Section 3. Figure 2 displays the percent difference in the $t_{e}$ duration between 3 -sided and 4 -sided exposure versus the column $t_{e}$ duration in minutes. A positive percentage change indicates that the column $t_{e}$ is longer, while a negative change indicates the opposite. From the figure, the column $t_{e}$ can be seen to exhibit a relatively similar duration to the beam $t_{e}$. The column $t_{e}$ duration is either equal to or slightly higher than the beam $t_{e}$ for every section and fire exposure.

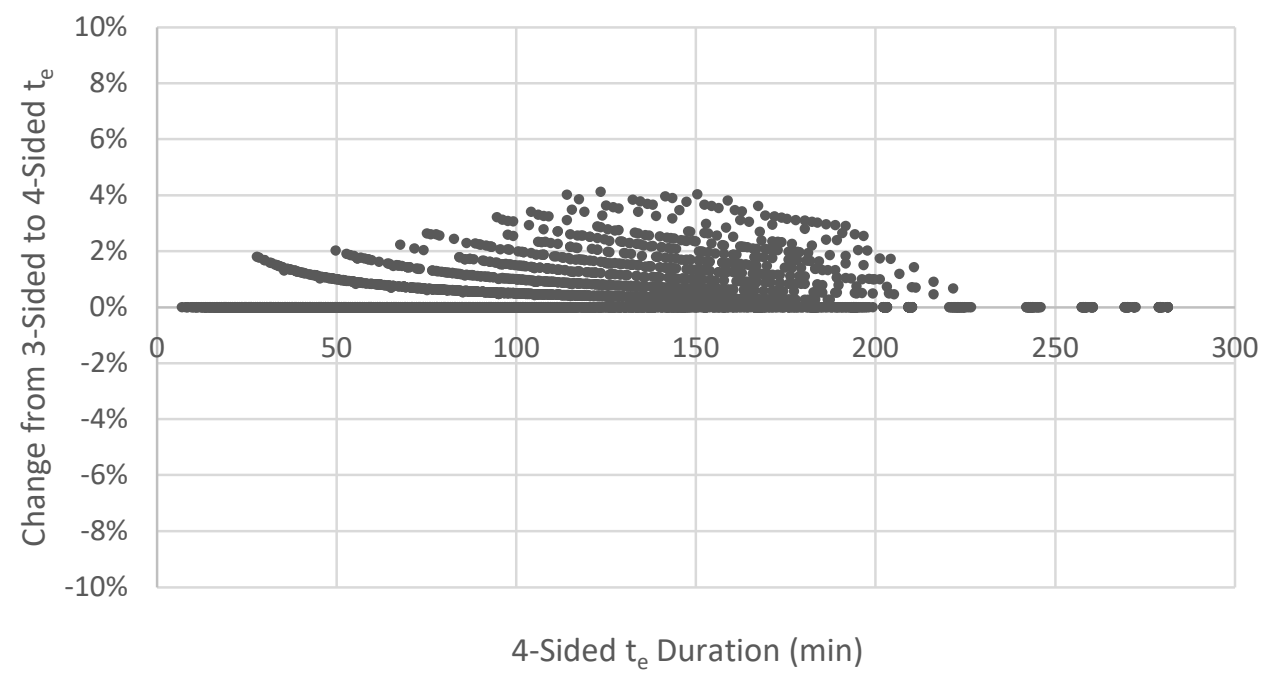

Fig. 2: Change in te from 3-Sided to 4-Sided Exposure

The increase in the column $t_{e}$ is attributed to the presence of the two variable zones of the AITP profile. In general, having only one or two variable zones has no impact on the $t_{e}$ duration; as the column's two variable zones are identical to the beam variable zone, and simply symmetrical license http://creativecommons.org/licenses/by-nc-nd/4.0/ 
about the neutral axis. However, when a section is short, or a design fire is long, the variable zones can overlap at the section's interior. In such a case, the AITP experiences higher internal temperatures, requiring an increase in the $t_{e}$ duration. Of the evaluated cases, $27 \%$ experienced the overlapping effect. Despite this overlapping presence, its impact on the AITP $t_{e}$ duration is relatively minor. On average, cases experiencing overlap required only a $0.29 \%$ increase to get to the column $t_{e}$. Likewise, the maximum required change, presented on Figure 2 , is only $4.13 \%$, representing an addition of $5.5 \mathrm{~min}$.

Given the similarity of the numerically derived $t_{e}$ for columns and beams, the AITP $t_{e}$ equation derived for 3-sided heating can be used for RC columns undergoing 4-sided exposure. Figure 3 highlights the suitability of the AITP $t_{e}$ and $\psi_{\text {size }}$ given by Equations $1 \mathrm{a}$ and $1 \mathrm{~b}$. The numerical and equation results indicate a good fit for the wide range of evaluated sections and design fires, justifying the use of the existing AITP $t_{e}$ equation. Furthermore, application of the $\psi_{\text {size }}$ results in a $t_{e}$ with far superior fit, demonstrating the validity of the existing $\psi_{\text {size }}$ and the importance of considering section dimensions when determining a time equivalent for RC elements.

(C) 2020. This manuscript version is made available under the CC-BY-NC-ND 4.0 license http://creativecommons.org/licenses/by-nc-nd/4.0/ 


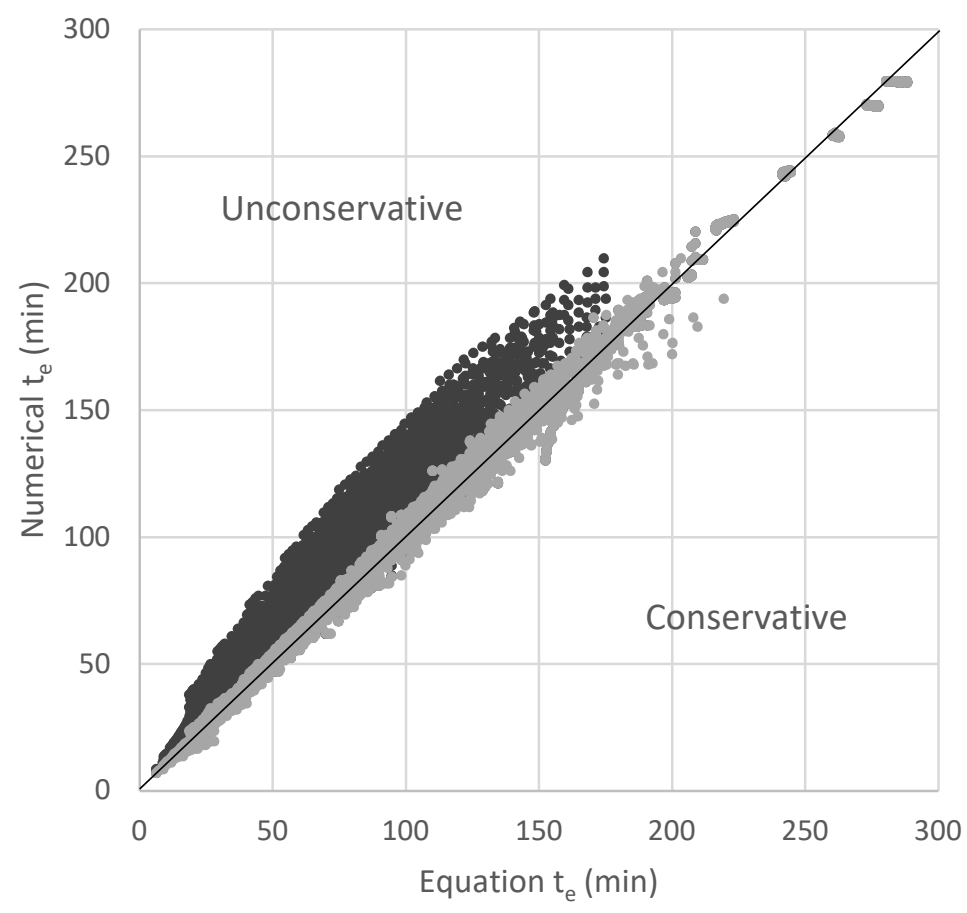

- Without Size adjustment Factor - With Size adjustment Factor

Fig. 3: Numerical vs. Equation $t_{e}$ with and without $\Psi_{\text {size }}$

\section{Assessment of the Mechanical Response of Fire Exposed RC Columns using the AITP $t_{e}$}

The application of the AITP $t_{e}$ equation in the performance-based design of RC columns undergoing natural fire exposure is assessed in this section. Performance-based requirements are often defined by serviceability and ultimate limit states. For RC columns, these two limit states can be best satisfied by the calculation of a section's moment-curvature $(M-\varphi)$ relationship at different axial load levels and the axial load-axial strain $(P-\varepsilon)$ relationship.

(C) 2020. This manuscript version is made available under the CC-BY-NC-ND 4.0 license http://creativecommons.org/licenses/by-nc-nd/4.0/ 


\subsection{Sectional Analysis Method}

The $M-\varphi$ and $P-\varepsilon$ relationship of RC columns during fire exposure can be simply established using the structural analysis program developed by El-Fitiany and Youssef (2009). The analysis has three main steps: (1) determine the internal thermal gradients of the section, (2) evaluate the concrete thermal and transient strains at elevated temperature, and (3) complete analyzing the section. The program makes the following assumptions: (1) plane sections remain plane during fire exposure, as previously validated up to $1200^{\circ} \mathrm{C}$ by El-Fitiany and Youssef (2011); (2) perfect bond exists between steel and concrete; (3) normal strength concrete (NSC) is used, and thus, explosive spalling can be ignored; (4) influence of concrete tensile cracks on heat flow is minor and can be ignored; and (5) geometrical nonlinearity is not considered.

\subsection{Study Methodology}

A series of RC columns were evaluated during both natural and standard fire exposures. Comparison of a section's $M-\varphi$ and $P-\varepsilon$ relationships during these two fire exposures is used to assess the accuracy of the AITP $t_{e}$. Considering the impracticality of presenting full $M-\varphi$ and $P-\varepsilon$ relationships for a large number of cross-sections and fire exposures, four key responses are identified from the relationships for general evaluation. These responses are the equivalent thermal induced strain recorded at section mid-height $\left(\varepsilon_{T}\right)$, the axial capacity at elevated temperature $\left(P_{T}\right)$, the moment capacity at elevated temperature $\left(M_{T}\right)$, and the initial curvature at elevated temperature $\left(\varphi_{i T}\right)$. For each evaluated section, these four responses were identified from the $M-\varphi$ and $P-\varepsilon$ relationships. It is necessary when analyzing columns to consider various axial load levels, of which, there are three load levels of particular importance: pure axial (1.OP), pure (C) 2020. This manuscript version is made available under the CC-BY-NC-ND 4.0 license http://creativecommons.org/licenses/by-nc-nd/4.0/ 
bending $(0.0 P)$, and the balanced condition $(0.4 P)$. The $0.4 P$ was chosen based on the observation made by Elbahy et al. (2008) that the balance condition at ambient temperature falls between $30 \%$ and $50 \%$ of the maximum axial load. El-Fitiany and Youssef (2018) observed a similar range for columns evaluated at elevated temperatures. Evaluation of a section at these three load levels allows for determination of the pure axial capacity $\left(P_{r T}\right)$ at $1.0 P$, the balance condition axial capacity $\left(P_{b T}\right)$ at $0.4 P$, the corresponding balanced condition moment capacity $\left(M_{b T}\right)$ at $0.4 P$, and the pure moment capacity $\left(M_{r T}\right)$ at $0.0 P$. Considering the four responses and the three axial load levels, twelve responses are recorded in total for each cross-section and fire exposure.

\subsection{Study Parameters}

Five column sections were selected for evaluation, Table 2 displays their properties. The studied parameters are: concrete strength at ambient temperature $\left(f^{\prime} c\right)$, section width $\left(b_{c}\right)$, section height

$\left(h_{c}\right)$, steel reinforcement ratio $\left(\rho_{s}\right)$, and aggregate type $(a g g$.$) of either siliceous (sil.) or calcareous$ (cal.). Thermal properties for normal strength concrete (NSC) with siliceous and calcareous aggregate are taken from Lie (1992). The steel ratio was represented as six bars, with three on the top and three on the bottom. The edge bars were placed at $55 \mathrm{~mm}$ from the column edge. A typical cross-section detail is presented in Figure 4.

(c) 2020. This manuscript version is made available under the CC-BY-NC-ND 4.0 license http://creativecommons.org/licenses/by-nc-nd/4.0/ 
Table 2: Parametric Study Column Properties

\begin{tabular}{|c|c|c|c|c|c|c|}
\hline ID & $\begin{array}{l}\mathbf{F}_{\mathbf{y}} \\
\mathrm{MPa}\end{array}$ & $\begin{array}{l}\mathbf{f}^{\prime} \mathbf{c} \\
\mathrm{MPa}\end{array}$ & $\begin{array}{l}\mathbf{b}_{\mathbf{c}} \\
\mathrm{mm}\end{array}$ & $\begin{array}{l}\mathbf{h}_{\mathbf{c}} \\
m m\end{array}$ & $\begin{array}{c}\boldsymbol{\rho}_{\mathrm{s}} \\
\%\end{array}$ & $\begin{array}{c}\text { agg. } \\
-\end{array}$ \\
\hline C1 & \multirow{5}{*}{400} & \multirow{2}{*}{30} & 300 & 300 & 2.0 & \multirow{3}{*}{ sil. } \\
\hline C2 & & & 400 & 400 & 1.5 & \\
\hline C3 & & \multirow{2}{*}{40} & 600 & 600 & 1.5 & \\
\hline C4 & & & 600 & 600 & 1.5 & \multirow{2}{*}{ cal. } \\
\hline C5 & & 30 & 500 & 800 & 1.0 & \\
\hline
\end{tabular}

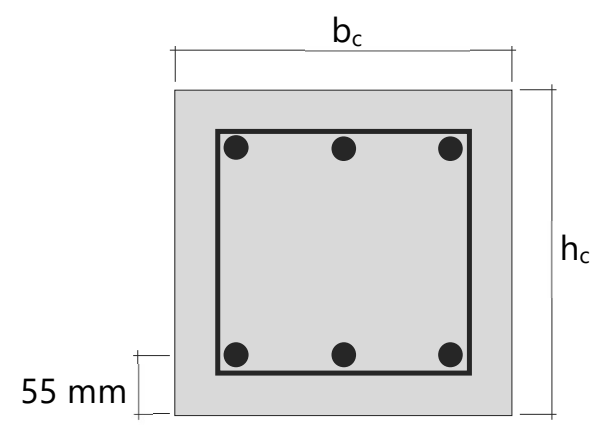

Fig. 4: Typical Column Cross Section

Five natural design fires were selected for evaluation, Figure 5 shows their profile. The five fires were developed using the Eurocode approach (EN 1991-1-2, 2002) to represent a range of possible natural fires as presented by Dembsey et al. (1995), Kirby et al. (1994), Lennon (2014), and Implementation of Eurocodes (2005). The fires can be broadly classified as medium, big, small, rapid hot, and long cool. To determine the AITP $t_{e}$, the key points of $t_{\max }, t_{\text {final, }}$ and $T_{\max }$ can be graphically identified from the fire curves and substituted into Equations $1 \mathrm{a}$ and $1 \mathrm{~b}$. Table 3 records the AITP $t_{e}$ duration with the applied $\varphi_{\text {size }}$ for the given design fires and cross-section dimensions. In total, the study considers 125 test cases using the four column sections, five design fire exposures, five equivalent standard fire exposures, and three axial load levels.

(c) 2020. This manuscript version is made available under the CC-BY-NC-ND 4.0 license http://creativecommons.org/licenses/by-nc-nd/4.0/ 


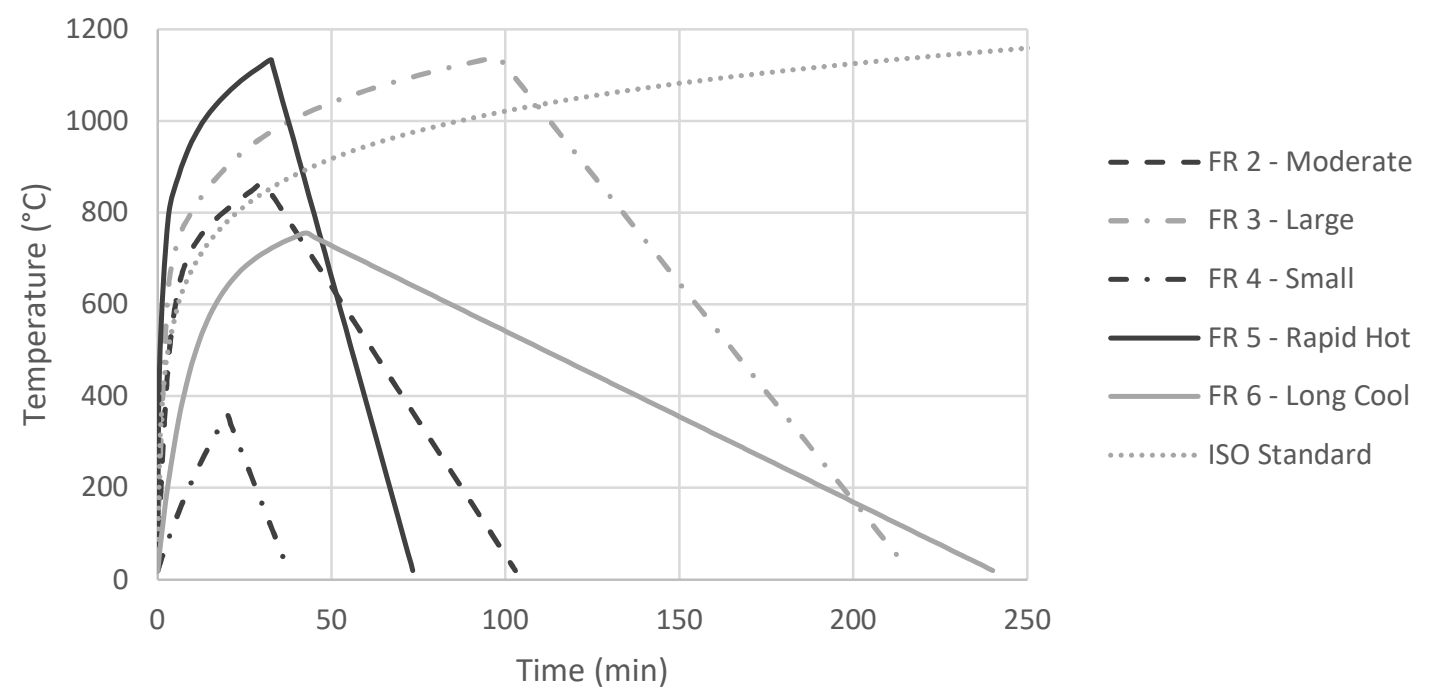

Fig. 5: Representative Design Fire Profiles

Table 3: AITP te for Study Design Fires

\begin{tabular}{l|cccc|l}
\hline \multicolumn{7}{c}{ te (min) } \\
\hline FR 2 & $\mathbf{3 0 0} \times \mathbf{3 0 0}$ & $\mathbf{4 0 0} \times \mathbf{4 0 0}$ & $\mathbf{6 0 0} \times \mathbf{6 0 0}$ & $\mathbf{5 0 0} \times \mathbf{8 0 0}$ \\
FR 3 & 197.0 & 68.9 & 72.7 & 70.8 & Moderate \\
FR 4 & 10.4 & 195.5 & 195.5 & 195.5 & Large \\
FR 5 & 128.4 & 128.4 & 128.4 & 128.4 & Rapid Hot \\
FR 6 & 90.2 & 96.2 & 108.2 & 102.2 & Long Cool \\
\hline
\end{tabular}

\subsection{Mechanical Response Assessment}

Figure 6 displays the full results for C1 exposed to the medium design fire FR 2 and the AITP $t_{e}$ standard fire. The ambient response is also provided as a baseline. The figure shows good correlation between the two fire events, with the AITP $t_{e}$ providing a conservative response at every point.

(c) 2020. This manuscript version is made available under the CC-BY-NC-ND 4.0 license http://creativecommons.org/licenses/by-nc-nd/4.0/ 
For the $P-\varepsilon$ response, the two fires induce a near identical trend and value throughout. At the initial point when no axial load is applied, the thermal strain $\left(\varepsilon_{T}\right)$ is found as -0.005 for both exposure fires. Strain increases with axial load similarly for both fires until the maximum axial load is identically reached at $2440 \mathrm{kN}$. For the $M-\varphi$ response, the relationship at $0.0 \mathrm{P}$ shows a strong correlation with the AITP $t_{e}$ recording only minorly conservative values throughout. At $0.4 \mathrm{P}$, the AITP $t_{e}$ deviates from the design fire response, but does so conservatively with lesser moment capacity and larger curvature. The final $M-P$ relationship defines the load capacity of the section. The four responses used to approximate the curve are identified and labelled. The AITP $t_{e}$ closely approximates the response of the design fire, with minorly conservative moment and axial responses.

Figures 7 to 10 display the comparison of the design fire and time equivalent standard fire in view of the four responses of $\varepsilon_{T,} \varphi_{i T_{1}} P_{T,}$ and $M_{T}$. For each of the 125 test cases, the AITP $t_{e}$ conservatively approximates the design fire result. This entails lesser moment and axial capacities, and larger initial curvatures and fire induced strains. The $\varepsilon_{T}$ displays the greatest variability, as concrete strain is highly susceptible to small changes in temperature. These figures confirm the application of the AITP $t_{e}$ in conservatively approximating the mechanical response of RC columns undergoing four-sided fire exposure. 

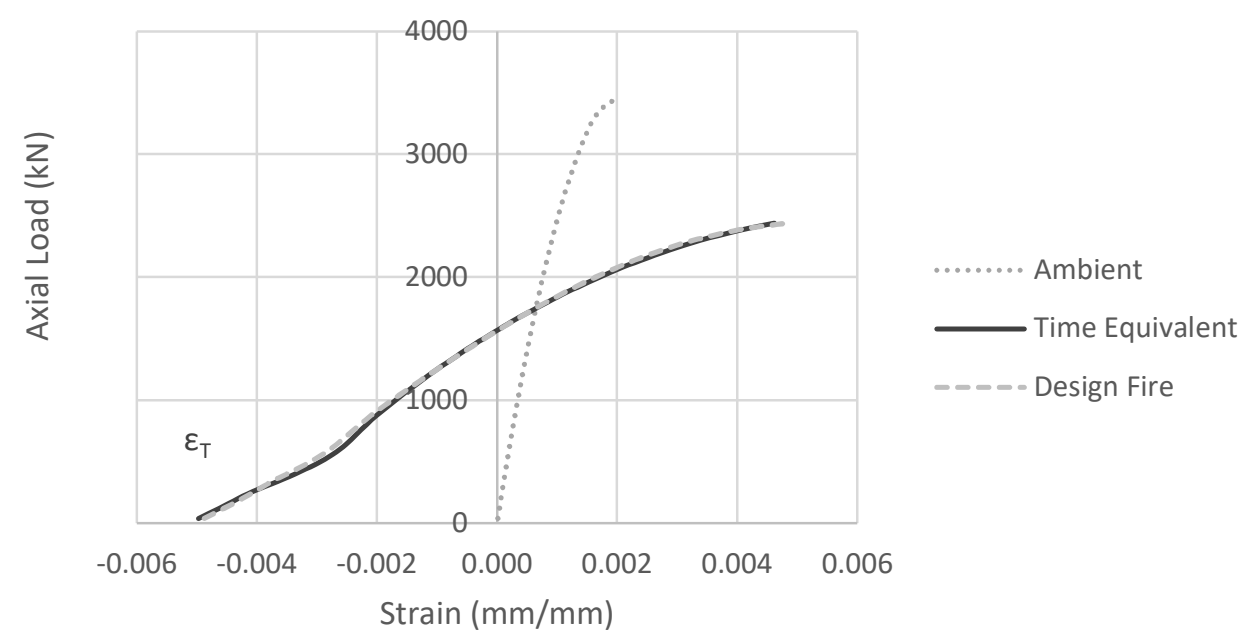

- - - - Design Fire

(a)

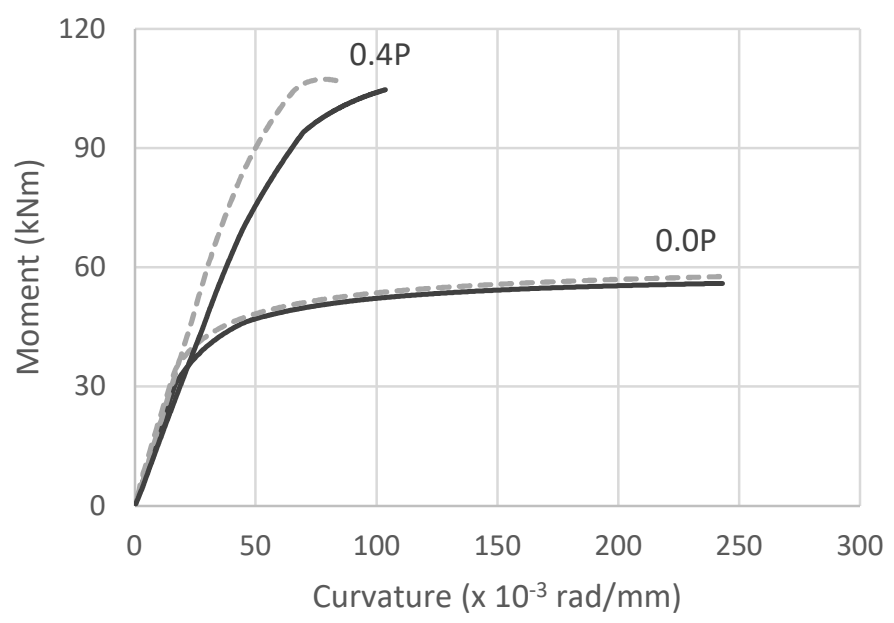

—_ Time Equivalent - - - - Design Fire

(b)
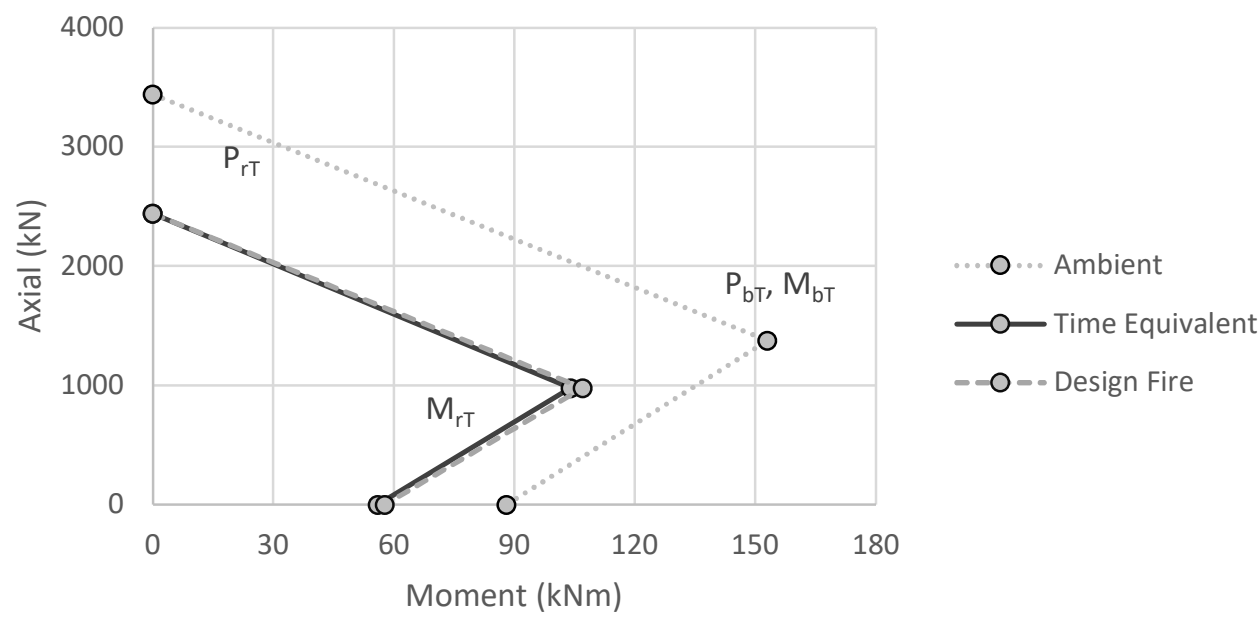

(c)

Fig. 6: Column C1 (a) Axial-Strain Relationship, (b) Moment-Curvature Relationship, (c) Moment-Axial Relationship

(c) 2020. This manuscript version is made available under the CC-BY-NC-ND 4.0 license http://creativecommons.org/licenses/by-nc-nd/4.0/ 


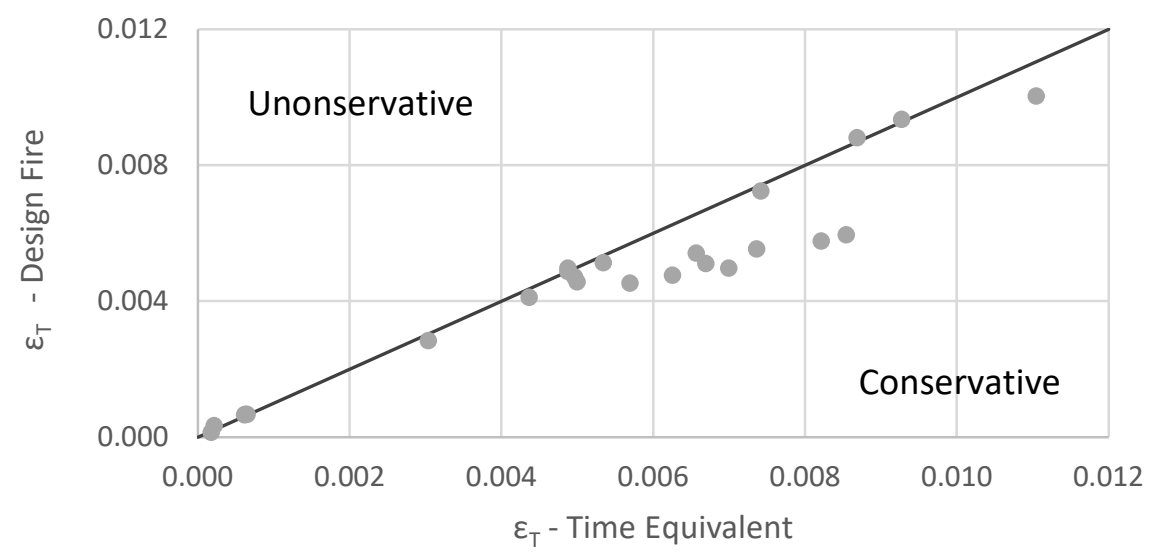

Fig. 7: Error in $\varepsilon_{\mathrm{T}}$ based on the Time Equivalent

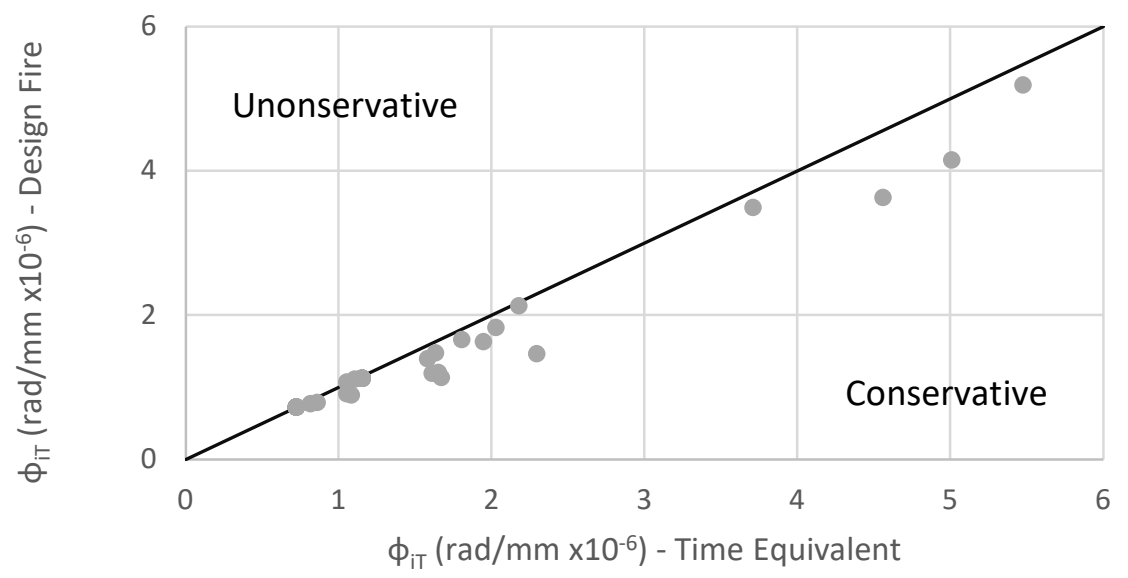

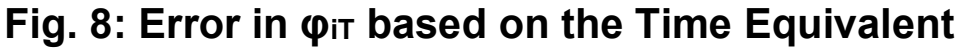

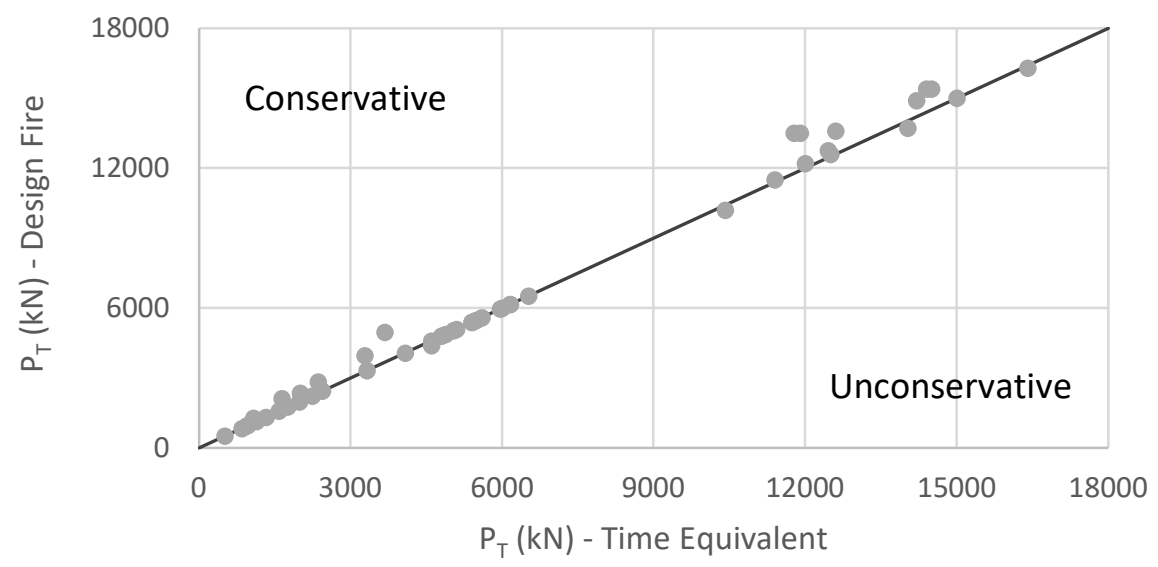

Fig. 9: Error in $\mathrm{PT}_{\mathrm{T}}$ based on the Time Equivalent

(c) 2020. This manuscript version is made available under the CC-BY-NC-ND 4.0 license http://creativecommons.org/licenses/by-nc-nd/4.0/ 


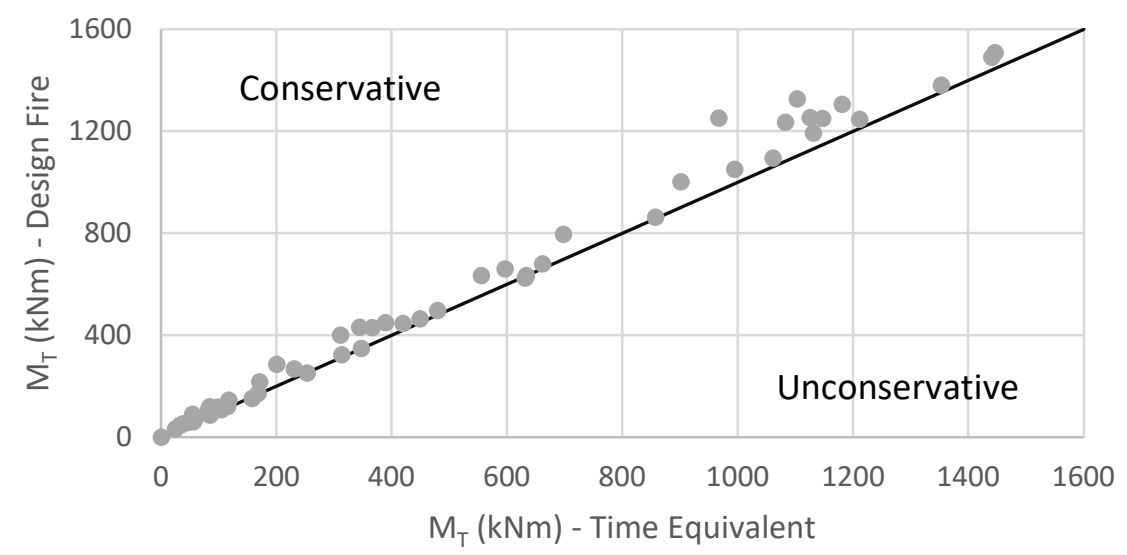

Fig. 10: Error in $\mathrm{MT}_{\mathrm{T}}$ based on the Time Equivalent

\section{Comparison with Existing Methods}

There are a number of time equivalent methods already existing in the literature; the earliest of which was proposed by Ingberg (1928). These methods vary greatly in their methodology, basing time equivalency on maximum element temperature, energy transfer, and load capacity. Despite the range of existing methods, few are applicable for reinforced concrete sections, and to the best of the author's knowledge, none consider the effect of 4-sided fire exposure for RC elements. In this section, a comparison is provided with two major existing time equivalent methods to demonstrate the improved suitability of the AITP $t_{e}$ and the importance of considering the unique effects of 4-sided fire exposure for RC columns.

The existing time equivalent methods presented by the Eurocode (EN 1991-1-2, 2002) and by Kodur et al. (2010) were selected for comparison. The Eurocode method was derived based on the work of Pettersson (1975) for protected steel columns (Buchanan, 2001). A modification factor

(c) 2020. This manuscript version is made available under the CC-BY-NC-ND 4.0 license http://creativecommons.org/licenses/by-nc-nd/4.0/ 
is provided in the code for application to RC elements. Despite the code's stated applicability to RC sections, Thomas et al. (1997) and Xie et al. (2017) have proven the method provides unreliable time equivalent values for RC members when assessing load capacity as the primary response. Regardless of other research findings, the wide spread use of the Eurocode makes it a highly suitable method for comparison. Kodur et al.'s method (2010) was derived for RC beams based on the energy transfer of a fire event. This method was previously found to be reasonably accurate in representing the internal temperatures of sections undergoing 3-sided fire exposure (Kuehnen and Youssef, 2019). Comparison with Kodur's method will best demonstrate the importance of considering 4-sided fire exposure when determining a time equivalent value.

Figure 11 displays the comparison between the AITP $t_{e}$ EN 1991-1-2 (2002), and Kodur et al. (2010). The comparison was made for column C2 $(400 \times 400 \mathrm{~mm})$ based on exposure to the five design fires given in Figure 5. Each of the four key responses is assessed at the axial load levels of $1.0 \mathrm{P}, 0.4 \mathrm{P}$, and $0.0 \mathrm{P}$. The key responses are recorded as a percent error from the value calculated using the design fire. A positive error indicates the time equivalent overestimates the actual design fire response, and a negative error indicates the opposite. It should be noted that some of the responses do not apply for every load level, therefore the figure is left blank for those cases. Furthermore, the $\varepsilon_{T}$ response is identical for each load level because it is only affected by temperature, not load.

(c) 2020. This manuscript version is made available under the CC-BY-NC-ND 4.0 license http://creativecommons.org/licenses/by-nc-nd/4.0/ 
The results presented in Figure 11 highlight the conservative nature of the AITP $t_{e}$ in relation with the existing methods. For every section response, design fire and axial load level; the AITP $t_{e}$ resulted in a conservative estimate of the design fire severity. In contrast, the Eurocode method rarely produced conservative results, often significantly over-approximating the section capacity and under-approximating the developed stains. Given the derivation of the Eurocode method for steel section's, this lack of applicability for RC columns is expected. Kodur's method is far more accurate than the Eurocode, but still demonstrates fair deviation in accuracy. There does not appear to be any pattern in Kodur's method for when it accurately, conservatively, or unconservatively approximates a design fire for a given response. As such, the method cannot be used to reliably approximate the severity of a concrete section undergoing 4-sided fire exposure. 

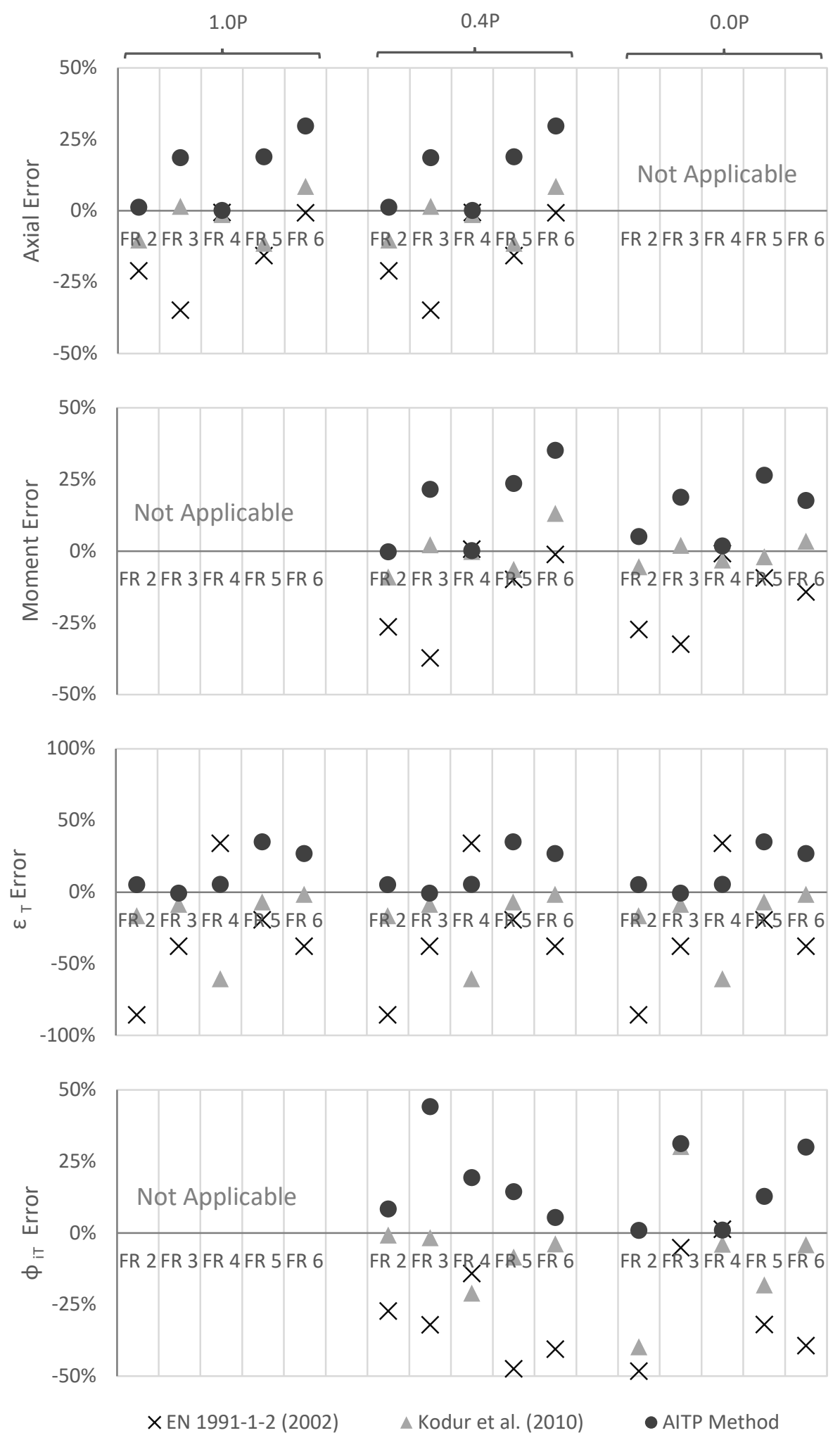

Fig. 11: Response of C2 for Existing Time Equivalent Methods

(c) 2020. This manuscript version is made available under the CC-BY-NC-ND 4.0 license http://creativecommons.org/licenses/by-nc-nd/4.0/ 


\section{Conclusion}

During a fire event, typical interior RC columns undergo 4-sided fire exposure. Existing time equivalent methods are largely focused on protected steel members or concrete beams undergoing 3-sided heating. Due to the unique thermal properties of concrete, the methods derived for protected steel members, such as given in the Eurocode (EN 1991-1-2, 2002), are highly inaccurate. Furthermore, the methods developed for RC beams undergoing 3-sided exposure (Kodur et al., 2010), are equally unreliable in representing fire severity as they ignore the additional thermal gradients that develop during 4-sided heating. To address this gap in the literature, the AITP time equivalent method by Kuehnen and Youssef (2019) was evaluated for application with RC columns. In the first part of the assessment, a parametric study was undertaken to determine the accuracy of the AITP $t_{e}$ in approximating section internal temperatures during 4-sided exposure. The resulting study outlined the suitability of the AITP general equation in producing conservative temperature profiles. In the second part of the study, the AITP $t_{e}$ was evaluated based on the structural performance of RC columns. It was shown that when assessing the moment-curvature, axial load-axial strain, and moment-axial load relationships; the AITP $t_{e}$ always produced conservative results in comparison to the true design fire response. A similar performance analysis was further undertaken for the existing methods from the Eurocode and Kodur et al. (2010), demonstrating the superior suitability of the AITP $t_{e}$ in consistently producing conservative approximations. Based on the results of the study, it is concluded that the AITP $t_{e}$ allows designers to reliably estimate the severity of a natural fire on an RC column for performance-based design. 


\section{Acknowledgments}

The authors are grateful for the financial support provided by the National Science and Engineering Research Council of Canada (NSERC), the India-Canada Center for Innovative Multidisciplinary Partnerships to Accelerate Community Transformation and Sustainability (ICIMPACTS), and Western University.

\section{References}

Alhadid, M. Behavior of Fire-Exposed RC Frames Before and After Jacketing. Diss. Department of Civil and Environmental Engineering, Western University, 2017.

ASCE 7-16. Minimum Design Loads and Associated Criteria for Building and Other Structures. American Society of Civil Engineers. Reston, VA, USA. 2016.

Buchanan, A.H. Structural Design for Fire Safety. $2^{\text {nd }}$ ed. Wiley, 2001.

Dembsey, N.A., P.J. Pagni, and R.B. Williamson. "Compartment Fire Experiments: Comparison with Models." Fire Safety Journal, vol. 25, no. 1, 1995, pp. 187-227.

Elbahy, Y., M.A. Youssef, and M.L. Nehdi. "Stress Block Parameters for Concrete Flexural Members Reinforced with Superelastic Shape Memory Alloys." Material and Structures, vol. 42, no. 10, 2008, pp.1335-1351.

El-Fitiany, S.F. and M.A. Youssef. "Assessing the Flexural and Axial Behaviour of Reinforced Concrete Members at Elevated Temperatures Using Sectional Analysis." Fire Safety Journal, vol. 44, no. 5, 2009, pp. 691-703.

El-Fitiany, S.F. and M.A. Youssef. "Fire Performance of Reinforced Concrete Frames Using Sectional Analysis." Engineering Structures, vol. 142, no. 1. 2017, pp. 165-181.

(c) 2020. This manuscript version is made available under the CC-BY-NC-ND 4.0 license http://creativecommons.org/licenses/by-nc-nd/4.0/ 
El-Fitiany, S.F. and M.A. Youssef. "Practical Method to Predict the Axial Capacity of RC Columns Exposed to Standard Fire." Journal of Structural Fire Engineering, vol. 9, no. 4, 2018, pp. 266-286.

El-Fitiany, S.F. and M.A. Youssef. "Stress-Block Parameters for Reinforced Concrete Beams during Fire Events." ACI Special Publication: Innovations in Fire Design of Concrete Structures, SP-279, 2011, pp. 1-40.

El-Fitiany, S.F., and M.A. Youssef. "Simplified Method to Analyze Continuous Reinforced Concrete Beams During Fire Exposure." ACl Structural Journal, vol. 111, no. 1, 2014, pp. 145-156.

EN 1991-1-2. Eurocode 1: Actions on Structures - Part 1-2: Actions on Structures Exposed to Fire. European Committee for Standardization. Brussels, Belgium. 2002.

Implementation of Eurocodes. Handbook 5 - Design of Buildings for the Fire Situation. Leonardo Da Vinci Joint Research Project, 2005.

Ingberg, S. "Tests on the Severity of Building Fires." Quarterly of the National Fire Protection Association, vol. 22, 1928, pp. 43-61.

ISO 834. Fire Resistance Tests - Elements of Building Construction. International Organization for Standards. Geneva, Switzerland. 2014.

Kirby, B.R., D.E. Wainman, L.N. Tomlinson, T.R. Kay, and B.N. Peacock. "Natural Fires in Large Scale Compartments." International Journal on Engineering Performance-Based Fire Codes, vol. 1, no.2, 1999, pp. 43-58.

Kodur, V.K.R., P. Pakala, and M.B. Dwaikat. "Energy Based Time Equivalent Approach for Evaluating Fire resistance of Reinforced Concrete Beams." Fire Safety Journal, vol. 45, no. 4, 2010, pp. 211220.

Kuehnen, R.T. and M.A. Youssef. "Equivalent Standard Fire Duration to Evaluate Internal Temperatures in Natural Fire Exposed RC Beams." Fire Safety Journal. Manuscript accepted for publication, June 2019.

(C) 2020. This manuscript version is made available under the CC-BY-NC-ND 4.0 license http://creativecommons.org/licenses/by-nc-nd/4.0/ 
Lennon, T. Results and Observations from Full-Scale Fire Test at BRE Cardington. no. 215-741, Building Research Establishment, Cardington, UK, 2004.

Lie, T.T. Structural Fire Protection. ASCE, 1992.

NFPA 1. Fire Code. National Fire Protection Association. Quincy, MA, USA. 2018.

Pettersson, O. The Connection Between a Real Fire Exposure and the Heating Conditions According to Standard Fire-Resistance Tests - With Special Application to Steel Structures. bulletin no. 39, Lund Institute of Technology - Division of Structural Mechanics and Concrete Construction, Lund, Sweden, 1975.

Thomas, G.C., A.H. Buchanan, and C.M. Fleischmann. "Structural Fire Design: The Role of Time Equivalence." 5th Asia-Oceania Symposium on Fire Science and Technology, Melbourne, Australia, 1997. Published by Fire Safety Science, 1997, pp 607-618.

Xie, P., A. Abu, and M. Spearpoint. "Comparison of Existing Time-Equivalent Methods and the Minimum Load Capacity Method." 10th Asia-Oceania Symposium on Fire Science and Technology, Tsukuba, Japan, 2015. Published by Fire Science and Technology, 2015, pp 263-271.

Youssef, M.A., M.A. Diab, and S.F. El-Fitiany. "Shear Capacity of RC Beams at Elevated Temperatures." Magazine of Concrete Research, vol. 67, no. 22, 2015, pp. 1190-1203.

(C) 2020. This manuscript version is made available under the CC-BY-NC-ND 4.0 license http://creativecommons.org/licenses/by-nc-nd/4.0/ 